Revista Internacional Educon, Volume I, n. 1, e20011003, set./dez. 2020

ISSN: 2675-6722 | DOI: https://doi.org/10.47764/ e20011003

\title{
Educação E A Relação Com O Saber: O Que Pensam E Sentem Os Professores
}

Education And The Relationship With Knowledge: What Do Teachers Think And Feel

La Educación Y La Relación Con El Conocimiento: Lo Que Piensan Y Sienten Los

Profesores

\section{CARLA ROBERTA SASSET ZANETTE}

${ }^{1}$ Secretaria Municipal da Educação (SMED)

RESUMO. Situado no contexto dos estudos da relação com o saber, teoria desenvolvida por Charlot (2000) $e$ sua equipe de pesquisa, este artigo tem o objetivo de compreender os sentidos atribuidos pelos docentes à educação no cotidiano escolar, evidenciando seus desejos e medos. Como procedimento metodológico, foi realizada pesquisa de campo, utilizando o balanço de saber como instrumento de pesquisa. Esse foi aplicado a quinze professores que atuam em escolas públicas de Educação Básica no município de Caxias do Sul. Os dados foram analisados e interpretados a partir dos pressupostos da Análise Discursiva de Moraes (2003). Os resultados evidenciam que o sucesso da aprendizagem dos estudantes e a percepção de que a educação pode transformar pessoas são os sentidos mais desejados pelos professores. Em contradição, a desvalorização profissional e a percepção de viver em uma sociedade anestesiada são os fatores que causam mais medos.

Educação. Docente. Relação com o saber. Sentido.

ABSTRACT: Situated in the context of the studies of the relationship with knowledge, a theory developed by Charlot (2000) and his research team, this article aims to understand the meanings attributed by teachers to education in school routine, highlighting their desires and fears. As a methodological procedure, field research was carried out, using the balance of knowledge as a research instrument. This was applied to fifteen teachers who work in public schools of Basic Education in the city of Caxias do Sul. The data were analyzed and interpreted based on the assumptions of Moraes' Discursive Analysis (2003). The results show that the success of students' learning and the perception that education can transform people are the meanings most desired by teachers. In contradiction, professional devaluation and the perception of living in an anesthetized society are the factors that cause the most fears.

Education. Teacher. Relationship with knowledge. Sense.

Os autores cedem à Revista Internacional Educon os direitos de primeira publicação do presente artigo. Aplicam-se os termos de uma licença Creative Commons Atribuição 4.0 Internacional (CC BY 4.0), que permite o uso irrestrito, a distribuição e a reprodução em qualquer meio desde que a publicação original seja corretamente citada. 
RESUMEN: Situado en el contexto de los estudios de la relación con el conocimiento, teoría desarrollada por Charlot (2000) y su equipo de investigación, este articulo tiene como objetivo comprender los significados que atribuyen los docentes a la educación en la rutina escolar, destacando sus deseos y miedos. Como procedimiento metodológico, se realizó una investigación de campo, utilizando el balance de conocimientos como instrumento de investigación. Esto se aplicó a quince docentes que laboran en escuelas públicas de Educación Básica de la ciudad de Caxias do Sul. Los datos fueron analizados e interpretados con base en los supuestos del Análisis Discursivo de Moraes (2003). Los resultados muestran que el éxito del aprendizaje de los estudiantes y la percepción de que la educación puede transformar a las personas son los significados más deseados por los docentes. En contraposición, la devaluación profesional y la percepción de vivir en una sociedad anestesiada son los factores que provocan más miedos.

Educación. Profesor. Relación con el conocimiento. Sentido.

\section{Introdução}

Desafiar-se a compreender a relação do docente com o saber implica investigar o complexo fenômeno da educação e a lidar com incertezas, dúvidas e (re)construções. É permitir-se transitar entre as descobertas e o prazer de pesquisar, nas rotas do desejo e do rigor científico.

Mobilizada pela resposta de Charlot (2010, p.155), quando questionado sobre que conselhos daria a quem deseja pesquisar educação, assim diz (referindo-se aos seus orientandos): "O que vocês querem saber e que ninguém ainda sabe, inclusive eu?”, desafio-me a compreender um pouco os sentidos atribuídos pelos docentes à educação.

Pensar a relação do docente com o saber pressupõe compreender o que pensam e sentem os professores quando o assunto diz respeito à educação, evocando seus desejos e medos. Nesse sentido, o objetivo da investigação está em compreender que sentido (s) os professores atribuem à educação, às práticas educativas, reconhecendo as emoções, os desejos e os medos que perpassam as relações consigo, com o outro e com o mundo.

A noção da relação com o saber busca compreender, entre outros aspectos, "como o sujeito apreende o mundo e, com isso, como se constrói e transforma a si próprio: um sujeito indissociavelmente humano, social e singular" (CHARLOT, 2005, p. 41). Para Charlot (2005), todo sujeito tem um tipo de relação com o saber, uma vez que o sujeito não tem uma relação com o saber, ele é relação com o saber. Estudar a relação com o saber é estudar o próprio sujeito enquanto se constrói por apropriação do mundo - portanto, também como sujeito aprendiz. (CHARLOT, 2005, p. 42, grifos do autor)

Refletir sobre as emoções dos docentes pressupõe adentrar em contradições de conflitos, tensões, desejos e saberes, que, relacionados, configuram a essência da docência. Cada um se sente e se diz professor a partir das experiências e vivências que o constituem, num processo de imbricamento entre o eu profissional e o eu pessoal. Desse modo, "a maneira como cada um de nós ensina está diretamente dependente daquilo que somos como pessoa quando exercemos o ensino.” (NÓVOA, 1992, p.16).

A questão fundamental é a necessidade de compreender as emoções que atravessam o ser e o fazer docente, no sentido de dar voz aos sonhos, desejos, medos, angústias, entre outros, num processo reflexivo sobre a relação do docente consigo mesmo, com os outros e com o mundo.

Sob esse viés, este estudo vincula-se aos pressupostos teóricos que tratam da relação com o saber, desenvolvida por Bernard Charlot e sua equipe de pesquisa, especialmente por encontrar em suas discussões uma abordagem que dialoga com questões relacionadas ao complexo fenômeno da educação e seus desdobramentos para o ensino e para a aprendizagem. Desse modo, conforme Charlot,

Para compreender os professores, seria preciso, portanto, interessar-se não somente por sua relação com o saber (com sua relação e a de seus alunos) mas também pela relação com o ensinar (com a situação e com a atividade de ensino). (CHARLOT, 2005, p. vi). 
Importante considerar que o professor é um sujeito incompleto, inconcluso, em constante aprendizagem. É, portanto, um ser singular, que assume uma posição social, relacionando-se com o ensinar e com o aprender.

$\mathrm{Na}$ intenção de explicitar os fundamentos teóricos que sustentam a relação com o saber, discorro nas próximas linhas reflexões sobre algumas concepções fundantes da teoria.

\section{Relação Com o Saber: Concepções e Fundamentos}

Compreender a educação, em toda sua complexidade, implica entendê-la como um processo cultural, social e intrínseco e constituinte ao ser humano. Para Charlot (2013, p.167), "É pela educação que as relações entre as gerações não é apenas uma relação de hereditariedade biológica; é, mais que tudo, uma herança cultural."

É a educação que permite ao homem questionar-se sobre si mesmo e sobre o mundo, refletir sobre suas ações e atitudes, de forma a reconhecer e respeitar o outro como parte constitutiva de si mesmo. Sendo assim, a noção da relação com o saber atenta-se a compreender, entre outros aspectos, "como o sujeito apreende o mundo e, com isso, como se constrói e transforma a si próprio: um sujeito indissociavelmente humano, social e singular" (CHARLOT, 2005, p. 41). Ou seja, é um sujeito que encontra a questão do aprender como condição humana.

Isso orienta Charlot (2000, p.45) a conceber a existência de uma sociologia do sujeito que entende a individualidade do sujeito e as relações que estabelece consigo, com os outros e com o mundo. Charlot define a concepção de homem como um ser humano incompleto, inacabado, que se apropria de um saber construído histórico-social-culturalmente. Por conseguinte, aprender é condição para o ser tornar-se humano. Nesse sentido, para o autor (2000, p. 52), o homem é resultado dessa construção, e, por ser um sujeito incompleto, "é um ausente de si mesmo". Partindo desse entendimento, para Charlot, um sujeito é:

\footnotetext{
i) um ser humano aberto ao mundo, movido por desejos e em relação com outros seres humanos; ii) um ser social, que nasce e cresce em um ambiente familiar, que tem uma posição em um espaço social, que está inscrito em relações sociais; iii) um ser singular, exemplar único da espécie, tem história própria, interpreta o mundo, atribui sentido a esse mundo, à posição que ocupa nele, às relações com os outros, à sua própria história, à sua singularidade. CHARLOT (2000, p.33).
}

A educação se constitui como um processo de aprendizagem a partir das relações do sujeito consigo, com o outro e com o mundo. Neste sentido, segundo Charlot (2000, p.53), a educação fundamenta-se na hominização (tornar-se homem); na singularização (ser único e exemplar); e na socialização (agindo, interagindo na sociedade e ocupando uma posição social).

Ainda, para o autor (2000, p.33), o sujeito é um ser constituído de desejos e movido por esses, bem como pela necessidade de aprender, ou seja, é o sujeito quem se mobiliza para a aprendizagem. É neste contexto que Charlot apresenta a diferenciação entre os conceitos de mobilização e motivação.

Na perspectiva de Charlot (2000, p. 55), a noção de mobilização remete à ideia de movimento, a um processo interno ao sujeito; ao passo que a motivação implica uma ação externa ao sujeito, desencadeada por alguém ou algo. Portanto, mobilizar-se para aprendizagem "é pôr recursos em movimento" [...], "é engajar-se em uma atividade originada por móbiles, porque existem boas razões para fazê-lo". Móbile entendido como um movimento interno, o desejo que leva à atividade. 
A noção de atividade fundamenta-se nos pressupostos de Leontiev, que a define como um conjunto de ações e operações, que se organizam em torno de um motivo (móbil) e de um objetivo (meta). Dito de outro modo, Charlot esclarece:

[...] faz-se necessário explicitar o que é uma atividade. Alexis Leontiev, colaborador de Vygotsky, explica que uma atividade é uma série de ações e operações, com um motivo e um objetivo (Leontiev, 198415). Por que faço isso? É o motivo. Para que o faço? É o objetivo. Como atingir esse objetivo? Realizando ações, que requerem operações. Uma atividade tem uma eficácia e um sentido. Ela é eficaz quando as operações permitem chegar ao resultado visado. O sentido da atividade, segundo Leontiev, depende da relação entre motivo e objetivo. Quando ambos coincidem, é mesmo uma atividade; senão, é apenas uma ação. (CHARLOT, 2009, p. 92).

A aprendizagem está atrelada ao sentido. Assim, para que o sujeito se mobilize, faz-se necessário que ele veja sentido no que está aprendendo. Aprender é uma forma de o sujeito apropriar-se do mundo, de se relacionar com o aprender, o que, segundo o autor, configura-se como uma relação epistêmica. Assim, o teórico (2000, p. 67, grifos do autor) afirma que "Aprender, é exercer uma atividade em situação: em um local, em um momento da sua história e em condições de tempo diversas, com a ajuda de pessoas que ajudam a aprender.”. Considerando a aprendizagem no contexto escolar, Charlot explica que:

\begin{abstract}
Para que o aluno se aproprie do saber, para que construa competências cognitivas, é preciso que estude, que se engaje em uma atividade intelectual, e que se mobilize intelectualmente. Mas, para que ele se mobilize, é preciso que a situação de aprendizagem tenha sentido para ele, que ele possa produzir prazer, respondera a um desejo. É uma primeira condição para que o aluno se aproprie do saber. A segunda condição é que esta mobilização intelectual induza a uma atividade intelectual eficaz. (CHARLOT, 2005, p. 54).
\end{abstract}

Charlot (2000) entende que as relações com o saber podem ser definidas sob três dimensões: epistêmica, de identidade e social. Sob a ótica epistêmica, Charlot denomina as figuras do aprender, as quais expressam as diferentes formas de relação do sujeito com os saberes, considerando suas histórias de vida, suas necessidades e intenções.

Aprender, na perspectiva epistêmica, significa apropriar-se de um saber materializado em livros, escolas, professores. É apropriar-se de saberes-objetos, de conteúdos intelectuais dos quais o sujeito não possui. O sujeito aprende também ao apropriar-se de um objeto virtual presente em objetos reais, numa relação com um saber-objeto, que se enuncia por meio da linguagem, especialmente, na modalidade escrita.

A relação com o saber pressupõe uma relação de identidade, que considera a história do sujeito, suas vivências, suas relações consigo e com o outro, que pode estar "fisicamente presente em meu mundo, mas também esse outro virtual que cada um leva dentro de si como interlocutor”. (Charlot, 2000, p.72).

Já a relação com o saber, como relação social, pressupõe ser capaz de regular a relação, a fim de encontrar a distância necessária entre si mesmo e com os outros. É compreender o processo de distanciação-regulação. A relação social não pode ser analisada separada das relações epistêmico e identitárias.

\title{
1.1 A relação do docente com o saber: uma relação consigo, com o outro e com o mundo
}

Compreendendo o entrelaçamento das relações que o professor estabelece com a educação e seus deslocamentos para as emoções e para as práticas de ensino, é possível pensar o docente como um sujeito singular, que assume posição social, uma vez que está inserido no contexto escolar, bem como alguém 
que ensina saberes historicamente construídos. Na concepção de Charlot (2005, p. 77), o “docente é, ao mesmo tempo, um sujeito (com suas características pessoais), um representante de uma instituição escolar (com direitos e deveres) e um adulto encarregado de transmitir patrimônio humano às jovens gerações (o que é uma função antropológica)".

Isso significa que, ao mesmo tempo em que os docentes buscam expressar suas relações com sua profissão, também evocam as relações que estabelecem consigo mesmo, com os outros e com o mundo, pois

Não há saber (de aprender) senão na Relação com o Saber (com o aprender). Toda Relação com o Saber (com o aprender) é também relação com o mundo, com os outros e consigo. Não existe saber (de aprender) se não está em jogo a relação com o mundo, com os outros e consigo mesmo. (CHARLOT, 2005, p.58).

Nessa perspectiva, investigar a relação do docente com o saber, especialmente sobre suas emoções, sentimentos e pensamentos atribuídos à educação no contexto contemporâneo, representa compreender os processos de sentido, de constituição humana, não a identificação de faltas e carências, que pressupõem julgamentos.

\section{Procedimentos Metodológicos}

Os procedimentos metodológicos adotados foram selecionados com vistas a resolver o objetivo proposto. Diante disso, tornou-se necessário eleger um percurso metodológico qualitativo que atendesse às descrições de sentido atribuídas pelos docentes às emoções, às interpretações percebidas acerca da educação e das práticas escolares.

Consoante Charlot (2001, p. 23), uma metodologia que se propõe a investigar a relação com o saber "deve se centrar no problema da mobilização do sujeito no campo do saber (do aprender) ou no confronto com este ou com aquele saber -mais precisamente ainda, deve se centrar nas fontes dessa mobilização e nas formas que ela assume."

Com vistas a compreender melhor os processos que constituem a relação do docente com as emoções e com os sentimentos, lancei mão do instrumento proposto por Charlot, denominado balanço de saber, também intitulado inventário de saberes, o qual, por meio de narrativas escritas, "visa identificar processos e, em seguida, construir constelações (configurações, tipos ideais), e não caracterizar indivíduos." (CHARLOT, 2001, p. 22)

O instrumento balanço de saber, consoante Charlot (2001, p. 37), representa a produção de um texto no qual o sujeitoavalia os processos e os resultados de sua aprendizagem. Charlot, juntamente a seus pesquisadores, ao propor os balanços de saber aos jovens de periferia, desenvolveu o seguinte enunciado: "Desde que nasci, aprendi muitas coisas; em casa, no bairro, na escola, em muitos lugares. O que me ficou de mais importante? E agora, o que eu espero?” (CHARLOT, 2001, p. 37). Nesse sentido, o enunciado foi adaptado assim: “O que pensam e sentem os professores sobre a educação?”.

De um modo mais específico, este estudo direciona seu olhar para o docente e suas relações com o saber. É o docente que se relaciona consigo, com os outros e com o mundo, nasdimensões epistêmica, de identidade e social. É um sujeito de saber que se relaciona como saber, nas formas que essa relação assume com as experiências e histórias de vida singulares; com as emoções; com a posição social que ocupa; com o ensino e a aprendizagem dos estudantes.

A opção pela metodologia qualitativa pode ser justificada na perspectiva de Moraes (2003, p. 193), ao considerar que "os materiais textuais constituem significantes a que o analista precisa atribuir sentidos e significados". 
Ao eleger as narrativas docentes como fonte de pesquisa, escolhi o método de análise textual discursiva, fundamentado em Moraes (2007), na intenção de interpretar o processo da relação do docente com o saber e entender os sentidos atribuídos à educação e aos seus deslocamentos para as emoções e pensamentos sobre as práticas educativas.

O exercício da docência é marcado por movimentos que se entrecruzam pelos processos de ensinar e de aprender. Neste sentido, as narrativas dos professores apontam indícios de rotinas que se delineiam no cotidiano da sala de aula. Rotinas essas marcadas, muitas vezes, pelo pouco incentivo à educação, à valorização profissional, entre outros.

A análise textual discursiva é definida como um processo de compreensão e reconstrução de significados, de análise e síntese, e pressupõe um engajamento intenso do pesquisador na prática de análise repleta de incertezas, angústias, percepções, sentimentos. É um caminho investigativo aberto a desvios e surpresas que se delineiam no percurso do processo, com interlocuções empíricas e teóricas, portanto, em sintonia com os pressupostos que tomam o cotidiano como alavanca para o conhecimento.

$\mathrm{Na}$ análise textual discursiva, movimentos de ida e vida ao material empírico são essenciais para a efetiva impregnação do pesquisador na decisão de escolhas, na compreensão das condições emergentes e nas ressignificações de elementos considerados já construídos. Consoante Moraes e Galiazzi (2007),

Análise Textual Discursiva é um processo integrado de análise e de síntese que se propõe a fazer uma leitura rigorosa e aprofundada de conjunto de materiais textuais, como objetivo de descrevêlos e interpretá-los no sentido de atingir uma compreensão mais complexa dos fenômenos e dos discursos a partir dos quais foram produzidos. (MORAES, GALIAZZI, 2007, p. 136).

Assim, na sequência, apresento os resultados e as discussões interpretadas a partir das narrativas produzidas nos balanços de saber.

\section{Sentidos Percebidos: o que pensam e sentem os professores}

A partir das leituras e releituras das narrativas produzidas pelos docentes, emergiram os sentidos evocados aos desejos e medos quando o assunto se refere à educação escolar. As narrativas produzidas foram analisadas e interpretadas à luz dos conceitos fundamentados na teoria da relação com o saber, bem como a partir das experiências e das vivências desta pesquisadora. Os professores participantes foram denominados de P1, P2, P3 e assim sucessivamente.

\subsection{O sentido da educação é a aprendizagem dos alunos}

De acordo com as narrativas produzidas e interpretadas, o sentido mais intenso enunciado pelos professores diz respeito à aprendizagem do aluno. Perceber o seu engajamento nas atividades intelectuais propostas em sala de aula, ou seja, em querer aprender é um dos sentimentos mais verbalizados pelos os docentes na esfera educacional. Neste sentido, afirmam os docentes:

O querer saber dos estudantes, a troca de saberes e o crescimento intelectual dos alunos. (P1)

[...] a dedicação dos alunos com as atividades, quando eles se envolvem e gostam da proposta de trabalho é muito significativo para mim. (P5)

Quando um aluno demonstra interesse e engajamento em um tópico estudado. (P8)

Quando os alunos abraçam a proposta de uma nova atividade. (P13) 
Por certo, quando há desejo de saber, por parte do aluno, isto é, quando ele "abraça a proposta", o professor sente-se realizado em ensinar, e, talvez, esse seja um dos grandes propulsores da profissão docente, principalmente, quando o saber tem sentido para o professor e para o aluno. De acordo com Charlot (2000, p.53), desejo "remete a uma alteridade que tem uma forma social, quer se trate do outro como pessoa, quer como objeto de desejo."

$$
\begin{aligned}
& \text { Quando vejo interesse em aprender nos olhos deles, valorização do nosso papel e } \\
& \text { de nós como individuo. (P4) } \\
& \text { Quando o que ensinamos tem algum significado para nós e para os estudantes. (P9) }
\end{aligned}
$$

Acompanhar o progresso dos discentes, mais especificamente dos que apresentam dificuldades, é motivo de realização dos professores, pelo fato de acompanharem suas trajetórias de aprendizagem, exercendo intervenções pedagógicas e constatando os avanços. Dessa perspectiva, perceber o engajamento do estudante a uma atividade intelectual proposta em sala de aula faz bater aceleradamente o coração do docente.

O meu coração bate mais forte quando percebo que um aluno com dificuldades está aprendendo. Sem dúvida, o progresso dos alunos. Amo quando participam e se entregam a uma proposta de sala de aula. (P2)

\subsection{Aprendizagem que transforma a si, ao outro e ao mundo}

Compreender que a aprendizagem transforma, de algum modo, a vida do estudante, permitindolhe sonhar e viver em condições mais dignas, é outro sentimento fortemente verbalizado pelo professor.

Charlot (2000, p. 65) entende que todo “(...) ser humano aprende: se não aprendesse, não se tornaria humano." É o entendimento de que o processo de humanização acontece por meio da educação que mobiliza o docente a continuar acreditando na educação e na vida.

As narrativas verbalizadas pelos professores clareiam o entendimento de que a aprendizagem construída no cotidiano escolar adquire muito mais sentido quando permite que o ser humano transforme a si próprio, aos outros e ao mundo que o cerca, de modo a transcendê-la para além dos bancos escolares. Nesse contexto, postulam-se os pressupostos da teoria da relação com o saber, pois, consoante Charlot (2000, p. 64), "um saber só tem sentido e valor por referência às relações que supõe e produz com o mundo, consigo e com os outros."

O fato de muitos docentes identificarem-se como "peça importante" na formação intelectual e humana dos alunos atribui um sentido valioso à atividade docente. Os diálogos que seguem evidenciam percepções dos professores acerca de transformações ocorridas a si próprios, aos alunos e à sociedade em geral, evidenciando a presença de estar no mundo.

Meu ânimo se renova quando vejo que faço a diferença na vida daqueles a quem ensino. Ver que o trabalho faz a diferença na vida dos alunos ou perceber que eu sou uma peça importante no processo de formação de outras pessoas. Saber que contribui com algum avanço, seja intelectual ou humano, faz-me sentir e ver sentido na existência. (P7)

Adquire força, nesse contexto, a dimensão de educação como possibilidade de mudança, de novas perspectivas de ser e existir no mundo. É o senso de realização e de produção de sentidos ao fazer, à docência.

A possibilidade de abrir horizontes. Transformar o aluno em leitor da vida. Alunos que atingem a excelência e mudam a sua realidade. Já valeu toda a luta. (P12) 
Por certo, o desejo de fazer a diferença na vida dos estudantes parece ser crucial nas falas dos professores, tendo em vista a intenção de buscar um ensino e uma aprendizagem que contribuam efetivamente com mudanças, tanto no docente quanto no aluno e no mundo em que vivem. Segundo Charlot (2000, p. 53), "esse movimento longo, complexo, nunca completamente acabado, que é chamado educação."

\subsection{Medo da desvalorização profissional}

As narrativas dos professores evidenciam diferentes sentidos no balanço das emoções, quando o assunto diz respeito à educação, quer pelos desejos, quer pelos medos.

A partir das percepções interpretadas, muitas inquietudes e ausências foram evocadas, mais especificamente no que se refere a situações envolvendo a desvalorização do professor e à sensação de solidão.

A constatação da desvalorização do docente, no contexto atual, parece ser um dos motivos mais cruciais que ocasionam medo ao professor. Mas o que leva a essa constatação? De quem parte essa desvalorização tão fortemente apontada pelos professores?

O termo desvalorização amplia-se no contexto das narrativas verbalizadas, abrangendo outros nomes que atendem ao mesmo campo semântico, no âmbito desta investigação, tais como: descrédito, desmerecimento, descaso, entre outros.

Nota-se que nessas palavras há a presença do prefixo de origem latina des, que significa negação ou ação oposta. Portanto, o uso desse prefixo retrata os medos que estão interligados e intensificados no tempo atual. As narrativas evidenciam essa constatação:

O descaso com que a educação vem sendo tratada pela própria sociedade, a meu ver, muito mais que pelos governos. Eu tenho medo de que o professor seja pouco valorizado pela sociedade, governo e alunos, acarretando na má qualidade, apesar de todos nossos esforços. (P7)

Conforme as interpretações das escritas docentes, a sociedade como um todo é o grande propulsor da desvalorização. Na dimensão de sociedade, incluem-se os segmentos que a constituem: alunos, pais, governantes, entre outros.

Essa desvalorização do professor, por sua vez, acaba repercutindo na educação e vice-versa, em um entrelaçamento, no qual “o pouco caso", quer à figura do professor, quer à educação, remete-se a uma relação interdependente, na medida em que a não valorização de um implica a do outro.

O pouco caso feito com a educação, ou melhor, dado à educação no nosso país. A falta de interesse por parte dos governantes, todo o descaso que escola e profissionais da educação sofrem. (P9)

As políticas públicas deturpadas, a falta de investimento público adequado, o descaso com os profissionais. O descaso como a educação vem sendo tratada no meio sociocultural e em políticas nacionais. (P 13)

Tanto é o medo do professor em relação ao descaso com políticas governamentais que surge a preocupação de que sejam implementadas medidas negativas na educação, as quais possam piorar a situação educacional no país. Políticas educacionais implementadas por pessoas que desconhecem ou que estão muito distantes da sala de aula, cujas cobranças destinar-se-ão ao professor.

Que pessoas distantes da realidade escolar queiram impor medidas incoerentes. Medo de políticas educacionais negativas. (P11) 
Com efeito, segundo as narrativas dos professores, a falta de investimento na educação representa um dos motivos da desvalorização profissional, mas não é o único. Falar em desvalorização pressupõe compreender a estreita relação de sentido que a constitui, pois junto a essa, somam-se o descrédito, o desrespeito, a desmotivação do professor, entre outros.

O estado de desvalorização percebido pelos docentes pode ser uma representação do processo recente de democratização do acesso à escola e seus desdobramentos, o qual ainda apresenta políticas públicas educacionais flutuantes. Ou seja, entre tantos aspectos, é fundamental para a valorização do professor a implementação de políticas públicas contínuas e propositivas às práticas cotidianas de sala de aula.

Como fenômeno múltiplo, a desvalorização sintetiza uma pluralidade de enfoques que se articulam em busca de sua compreensão e se manifestam na falta de interesse, no desrespeito, na intolerância, entre outros, por parte dos alunos, das famílias, dos gestores públicos e, muitas vezes, dos próprios colegas de profissão.

A falta de limites e de respeito da maioria dos estudantes. A falta de interesse e participação da maioria das famílias. O descaso, o desrespeito, a falta de comprometimento especialmente pelos gestores. (P15)

A falta de consideração, valor e respeito à figura do professor. A intolerância (dos diferentes envolvidos: professores, estudantes, comunidade escolar...) (P8)

Falta de respeito por parte de alunos, colegas e pais. (P2)

A indiferença, a falta de respeito. (P9)

A falta de autoridade que o professor está tendo. (P13)

\subsection{Medo de viver em uma sociedade anestesiada}

Algumas narrativas docentes são interpretadas em relação ao medo de viver em uma sociedade "silenciada" e "anestesiada", que torna o professor incapaz de se mobilizar para modificar o cenário educacional contemporâneo.

No que tange a essa temática, há a denúncia de uma opressão velada exercida sobre professor, que o faz silenciar e calar. Observo o medo que os professores têm de expressar suas opiniões e sofrerem represálias.

Provavelmente, esse medo seja evocado devido à utilização de gravações em sala de aula, não raras vezes, distorcendo a fala do professor. Ou ainda, pelas repercussões na mídia de fatos expondo discursos de professor sobre o cotidiano escolar.

Para os interlocutores empíricos, a liberdade de expressão está em jogo, pois, o professor se sente fiscalizado pelo aluno, pelos colegas, pela família e pela sociedade.

A violência e a falta de foco no saber, além de tentativas veladas, em alguns casos, de silenciamento por parte da sociedade em geral. A impossibilidade do diálogo. O medo de perder a liberdade de falar o que se pensa e sentir a opressão, pois os espaços estão limitados. (P3)

Sentir-se vigiado, fiscalizado e sozinho é o medo que ronda os professores, bem como a sensação de não poder exercer, com liberdade e autonomia, sua profissão. O professor se reconhece em um paradoxo, uma vez que a mesma sociedade que lhe cobra resultados, quer na questão de educação de atitudes e valores, quer no ensino de saberes formais, é a mesma que o condena, muitas vezes, considerando-o inimigo e desvirtuando sua função profissional. Mas por que o professor é considerado inimigo? Por manifestar sua opinião? Por proporcionar diálogos e debates com diferentes pontos de vista? São questões que me invadem o pensamento neste momento. 
A repressão, a falta de informação, o preconceito, a falta de investimentos. Eu não saber lidar com as diferenças. E de acordo com as últimas notícias, a nova "fiscalização" nas escolas. (P4) O futuro é incerto, mas o medo é a partir de condenações aos docentes, o professor ser visto ambições como inimigo e sofrer represálias por alguma colocação. (P14)

O que mais me dá medo é a desmotivação e a acomodação de tantos. Adolescentes sem e determinação. A sociedade, a desestruturação familiar anestesiou os jovens. A preguiça, a comodidade, a falta de incentivo e vontade me dá muito medo. (P6)

\section{Considerações finais}

A proposta deste artigo centrou-se em compreender a relação dos docentes com a educação, com os sentidos atribuídos às emoções, evidenciando os desejos e medos que circundam o cotidiano escolar e as práticas educativas.

A partir das análises e interpretações percebidas nas narrativas docentes, entendo que a relação do professor com a educação perpassa as emoções, os sentimentos, o ensino e a aprendizagem. Os professores sentem-se realizados ao ver seus alunos aprendendo, mobilizando-se para o conhecimento. Do mesmo modo, quando os professores reconhecem que o ensino e, por decorrência, a aprendizagem escolar tiveram o propósito de transformar a vida dos alunos e sua relação com o mundo.

Em contradição ao sentimento de realização, os professores revelam os medos que mais circundam a educação, ou seja, a desvalorização profissional e o fato de viver em uma sociedade anestesiada, que não age e reage contra às ofensas emitidas ao professor e à educação.

Partindo dos sentidos evocados nas narrativas dos balanços de saber, procurei fundamentar a relação do docente com o saber por meio de uma interlocução teórica somada às interpretações das emoções e pensamentos acerca da educação contemporânea.

\section{Referências}

Charlot, Bernard. Da relação com o saber: elementos para uma teoria. Porto Alegre: Artes Médicas, 2000.

Charlot, Bernard. Relação com o Saber, Formação dos Professores e Globalização. Porto Alegre: Artes Médicas, 2005.

Charlot, Bernard. A relação com o saber nos meios populares. Uma investigação nos liceus profissionais de subúrbio. Porto: Livpsic, 2009.

Charlot, Bernard. Da relação com o saber às práticas educativas. São Paulo: Cortez, 2013.

Moraes, Roque. Uma tempestade de luz: a compreensão possibilitada pela análise textual discursiva. Ciência e Educação, Bauru/São Paulo, v. 9, n. 2, p. 191-210, 2003.

Moraes, Roque \& Galiazzi, Maria do Carmo. Análise textual discursiva. Ijuí: Ed. da Unijuí, 2007.

Nóvoa, Antônio. Vidas de Professores. Porto: Porto Editora, 1992. 
Sobre a Autora:

\section{CARLA ROBERTA SASSET ZANETTE ${ }^{1}$}

(D) ORCID: ORG/0000-0001-7609-1330

Doutora em Educação pela Universidade de Caxias do Sul, Diretora Pedagógica da Secretaria Municipal da Educação, Professora da Educação Básica.

E-mail: crsasset@ucs.br

Submetido: 07 ago. 2020

Aceito: 21 ago. 2020 